\title{
Efficacy of Vitamin D Supplementation After Bariatric Operation: Letter to the Editor
}

\author{
Dimitrios Tsamis
}

Published online: 14 December 2014

(C) Springer Science+Business Media New York 2014

Dear Editor,

I read the article "Vitamin D Supplementation Efficacy: Sleeve Gastrectomy Versus Gastric Bypass Surgery" [1]. I was concerned about the aim of the study trying to show any differences after two bariatric operations in a small group of patients (11 versus 12 patients). Three months after the bariatric procedures and after the intense supplementation with vitamin D, $26.1 \%$ of patients had vitamin D deficiency in both groups. I think that this study is based in a very small population, without any power analysis data given. The authors do not also reveal the possible problems with unmasking subclinical parathyroid glands adenomas with intensive vitamin D supplementation [2]. The rate of these problems and the rate of preoperative secondary hyperparathyroidism could not possibly be revealed with such a small group of patients [3]. I think a study with more patients will enlighten us about the possible role of vitamin D supplementation after these two bariatric procedures. Assessment of vitamin D deficiency should also be performed after a longer period after the operation.

Conflict of Interest D. Tsamis has no conflict of interest.

\section{References}

1. Moore CE, Sherman V. Vitamin d supplementation efficacy: sleeve gastrectomy versus gastric bypass surgery. Obes Surg. 2014;24(12): 2055-60. doi:10.1007/s11695-014-1261-7.

2. Asghar A, Ikram M, Islam N. A case report: giant cystic parathyroid adenoma presenting with parathyroid crisis after Vitamin D replacement. BMC Endocr Disord. 2012;28:12-4.

3. Luger M, Kruschitz R, Langer F, Prager G, Walker M, Marculescu R, et al. Effects of omega-loop gastric bypass on vitamin $\mathrm{D}$ and bone metabolism in morbidly obese bariatric patients. Obes Surg. 2014 Nov 8. [Epub ahead of print]
D. Tsamis $(\bowtie)$

St Mark's Hospital, 5J Nicoll Road, Willesden NW10 9AX London, UK

e-mail: tsamisdim@hotmail.com 